\title{
Dopamine Release and Uptake Dynamics within Nonhuman Primate Striatum In Vitro
}

\author{
Stephanie J. Cragg, Christopher J. Hille, and Susan A. Greenfield \\ University Department of Pharmacology, Oxford, OX1 3QT, United Kingdom
}

\begin{abstract}
The putamen of the human striatum is a heterogeneous nucleus that contains the primary site of loss of dopamine (DA) in Parkinson's disease (PD). Furthermore, different functional domains of the putamen are heterogeneously susceptible to DA loss, and yet the dynamic regulation of extracellular DA concentration $\left([D A]_{0}\right)$ and comparison between domains has not been explored in the primate brain. In these studies, DA was measured in real time using fast-scan cyclic voltammetry at a carbon-fiber microelectrode in vitro in striatal sections from the common marmoset (Callithrix jacchus). [DA]。 released by a single stimulus pulse varied threefold along a ventromedial-dorsolateral axis. DA uptake was via the DA transporter (GBR12909 sensitive, desipramine insensitive). On the basis of data modeling with simulations of Michaelis-Menten kinetics, rate maximum, $V_{\max }$, varied with region: both $[\mathrm{DA}]_{\circ}$ and $V_{\max }$ were greatest in regions most vulnerable in PD. These differences were reflected in part by re-
\end{abstract}

gional variation in $\mathrm{DA}$ content. $[\mathrm{DA}]_{\mathrm{o}}, V_{\text {max }}$, and regional variation were two- to threefold greater than in rodent caudatoputamen.

In addition, steady-state $[D A]$ at physiological firing rates in primate striatum was controlled by depolarization frequency, uptake, and presynaptic autoreceptors. Furthermore, regulation of $[\mathrm{DA}]_{\mathrm{o}}$ by these mechanisms differed significantly between limbic- and motor-associated domains.

These data indicate interspecies heterogeneity in striatal DA dynamics that must be considered when extrapolating behavioral and drug responses from rodent to the primate brain. Moreover, the heterogeneity demonstrated within the primate putamen in the availability and dynamic regulation of DA may be central to understanding DA function in health, cocaine abuse, and disease.

Key words: Parkinson's disease; basal ganglia; DA transporter; DA uptake; autoreceptor; cocaine
The putamen of the primate striatum performs major sensorimotor, cognitive, and emotive functions. A central component of the basal ganglia, the putamen receives the main corticostriatal inputs from the motor, premotor, supplementary motor, and sensorimotor cortices (Kunzle, 1975, 1977, 1978; Jones et al., 1977; Selemon and Goldman-Rakic, 1985). In turn, loss of dopaminergic innervation underlies the motor dysfunctions of Parkinson's disease (PD) (Hornykiewicz, 1966; Kish et al., 1988). Furthermore, studies using $\left[{ }^{18} \mathrm{~F}\right]$-dopa positron emission tomography imaging, HPLC, and $\left[{ }^{3} \mathrm{H}\right]$-mazindol binding in $\mathrm{PD}$ and in intermediate primate 1-methyl-4-phenyl-1,2,3,6,-tetrahydropyridine (MPTP)-parkinsonism indicate that dopamine (DA) deinnervation follows a regionspecific pattern of vulnerability, beginning in dorsolateral putamen (Elsworth et al., 1987; Kish et al., 1988; Moratella et al., 1992; Antonini et al., 1995). The functions of the intact putamen are topographically compartmentalized along a dorsolateral-ventromedial axis (Haber and McFarland, 1999) with respect to corticostriatal (Kunzle, 1975, 1977; Selemon and Goldman-Rakic, 1985; Goldman-Rakic and Selemon, 1986), meso/nigrostriatal (Szabo, 1980; Parent et al., 1983; Smith and Parent, 1986; Lynd-Balta and Haber, 1994), thalamostriatal (McFarland and Haber, 2000), amygdalostriatal (Russchen et al., 1985), and striatopallidal projections (Hazrati and Parent, 1992), and somatotopic organization (the activity of putaminal neurons is related to specific body parts) (Crutcher and DeLong, 1984; Alexander and DeLong, 1985). Functionally related striatal areas thus share similar afferentation, somatotopy, susceptibility of mesostriatal input to degeneration, and in addition, modulation by cocaine (Bradberry et al., 2000).

Because mesostriatal projection neurons differ in expression levels of DA regulatory proteins, e.g., $\mathrm{D}_{2}$-like receptor, DA trans-

Received June 19, 2000; revised Aug. 17, 2000; accepted Aug. 17, 2000.

S.J.C. was funded by an E. P. Abraham Research Fellowship (Keble College, Oxford) and Novartis Pharma; C.J.H. was funded by Synaptica Ltd. We thank Dr. A. Whatham, Dr. J. Roeper, E. Mann, P. W. Tynan, and E. Howse for their contributions, advice, and technical assistance.

Correspondence should be addressed to Dr. S. J. Cragg, University Department of Pharmacology, Oxford OX1 3QT, UK. E-mail: stephanie.cragg@pharm.ox.ac.uk. Copyright (c) 2000 Society for Neuroscience $0270-6474 / 00 / 208209-09 \$ 15.00 / 0$ porter (DAT) (Shimada et al., 1992; Blanchard et al., 1994; Hurd et al., 1994; Sanghera et al., 1994; Haber et al., 1995), there may be as yet unappreciated regional differences in the regulation, and thus role, of $[\mathrm{DA}]_{\mathrm{o}}$ within primate putamen that may be of key consequence not only to normal basal ganglia function but also to modulation by substances of abuse and susceptibility to degeneration.

Fast-scan cyclic voltammetry at a carbon-fiber microelectrode offers spatially discrete observations of dynamic changes in [DA] in "real-time" and has been used to study striatal DA mechanistics extensively in rodents [e.g., rat (Garris et al., 1994; Jones et al., 1995), mice (Giros et al., 1996; Jones et al., 1998), guinea pig (Cragg and Greenfield, 1997)] in which striatal organization differs from primates, e.g., in limbic-associated afferents and efferents (Selemon and Goldman-Rakic, 1985; Lynd-Balta and Haber, 1994; Haber and McFarland, 1999) and anatomically by division of caudate and putamen by the internal capsule. It is essential to our understanding of primate striatal DA function that we study the primate directly.

We have explored in the putamen of the nonhuman primate, the common marmoset, the dynamics of extracellular DA and regulation by firing frequency, uptake kinetics, and autoreceptors. These dynamics are compared (1) in rodents and (2) between limbic- and motor-associated subdivisions of putamen to evaluate the predictive value of nonprimate data to primates, and moreover to gain directly insights into the operation of the primate striatum in health, substance abuse, and pathology.

\section{MATERIALS AND METHODS}

Brain slice preparation. Striatal slices $(400 \mu \mathrm{m})$ were prepared from male marmosets (age 1-2 years) from an established colony after overdose of pentobarbitone (intraperitoneal) or from male albino guinea pigs (200$350 \mathrm{gm}$ ) as described previously (Rice et al., 1997) in ice-cold, HEPESbuffered physiological saline saturated with $95 \% \mathrm{O}_{2} / 5 \% \mathrm{CO}_{2}$ and using a Vibratome (Lancer Series 1000). The mid to rostral range of slices that was used corresponds to anterior-posterior (AP) $9.5-11.75 \mathrm{~mm}$, marmoset (Stephan et al., 1980) and approximately A12.0-13.5 mm, guinea pig (Rapisarda and Bacchelli, 1977). All recordings were made at $31-32^{\circ} \mathrm{C}$ in bicarbonate-buffered artificial CSF $\left(\mathrm{aCSF} ; 95 \% \mathrm{O}_{2} / 5 \% \mathrm{CO}_{2}\right)$ as described previously (Rice et al., 1997). We defined three function-related recording sites in marmoset putamen (see Fig. 2): ventromedial (close to ventrome- 
dial edge of internal capsule), mid, and dorsolateral, which according to distinct frontal cortical inputs serve emotive/limbic-associated (orbital and medial prefrontal cortex), cognitive (dorsolateral prefrontal cortex), and sensorimotor functions, respectively (Selemon and Goldman-Rakic, 1985; Goldman-Rakic and Selemon, 1986; Haber and McFarland, 1999).

Voltammetry and microelectrodes. $[\mathrm{DA}]_{\mathrm{o}}$ was measured using fast-scan cyclic voltammetry at a beveled carbon-fiber microelectrode (CFM) (diameter: tip to $6 \mu \mathrm{m}$; tip length: $\sim 30 \mu \mathrm{m}$; MPB Electrodes, London) using a Millar Voltammeter (PD Systems) as described previously (Cragg and Greenfield, 1997; Cragg et al., 1997; Rice et al., 1997). Scan rate was 800 $\mathrm{V} / \mathrm{sec}$; scan range was -0.7 to $+1.3 \mathrm{~V}$ to $-0.7 \mathrm{~V}$ versus $\mathrm{Ag} / \mathrm{AgCl}$, and the sampling frequency was $4-8 \mathrm{~Hz}$. Illustrated voltammograms are faradaic currents obtained by subtraction of background current. Identification of the released substance as DA was confirmed by comparison in situ and in DA calibration of oxidation and reduction potentials $(+540$ and $-180 \mathrm{mV}$ vs $\mathrm{Ag} / \mathrm{AgCl}$, respectively). Contributions from the monoamine oxidase (MAO)-metabolite 3,4-dihydroxyphenyl-acetic acid (DOPAC) or norepinephrine (NE) were determined as minimal from experiments including MAO-inhibition (pargyline) and NE uptake inhibition (desipramine). Electrodes were calibrated in 1-2 $\mu \mathrm{M}$ DA in aCSF. Sensitivity to DA was typically $2-7 \mathrm{nA} / \mu \mathrm{M}$. The minimum detection limit for [DA] was $20-40$ nM.

Electrical stimulation. Electrical stimulation was at local, surface bipolar electrodes as described previously (Cragg and Greenfield, 1997). Stimulus pulses $(0.1 \mathrm{msec}$ pulse width, $10 \mathrm{~V})$ were applied either singly or in trains lasting $3 \mathrm{sec}$. Some experiments used a high-intensity stimulation $(100 \mathrm{~Hz}$,

$\sim 20 \mathrm{~V}, \leq 0.5 \mathrm{sec}$ train) to evoke high $[\mathrm{DA}]_{\mathrm{o}}\left(>10 \times K_{\mathrm{m}}\right.$ of DAT $)$ at which DA uptake rate, $V$, approaches $V_{\max }$

HPLC analysis of striatal dopamine tissue content. After voltammetric studies, striatal tissue was subdissected in ice-cold aCSF $\left(95 \% \mathrm{O}_{2} / 5 \%\right.$ $\mathrm{CO}_{2}$ ) using a tissue punch method to sample ventromedial and dorsolateral regions, snap-frozen in liquid $\mathrm{N}_{2}$, and stored at $-80^{\circ} \mathrm{C}$. The tissue was thawed on ice and homogenized in 50-100 vol of $0.1 \mathrm{~mm} \mathrm{HClO}_{4} / 4.5 \mathrm{~mm}$ EDTA using an ultrasonic disintegrator (20 sec, SONIPREP 150) and centrif uged at $17,000 \times g$ for 15 min (Sigma $3 \mathrm{~K} 10$, rotor Nr $12154-\mathrm{N})$. The supernatant was eluted and centrifuged at $17,000 \times \mathrm{g}$ for $2 \times 15 \mathrm{~min}$, and the final supernatant was stored before analysis of DA content at $-80^{\circ} \mathrm{C}$. The HPLC consisted of a delivery pump (Pharmacia LKB 2248), a column (APEX I Octadecyl, $5 \mu \mathrm{M}, 4.6 \times 100 \mathrm{~mm}$ ), and an electrochemical detector (Waters $46 \mathrm{~V}$ ) set at a potential of $0.7 \mathrm{~V}$ versus an $\mathrm{Ag} / \mathrm{AgCl}$ reference electrode. Mobile phase consisted of $0.1 \mathrm{M}$ citric acid, $0.1 \mathrm{M} \mathrm{Na}_{2} \mathrm{HPO}_{4}, \mathrm{pH}$ $3.7,2.5 \mathrm{~mm}$ hexanesulfonic acid/acetonitrile/methanol (92:3:5) and was pumped at $0.8 \mathrm{ml} / \mathrm{min}$.

Data analysis. Voltammetric data were acquired and analyzed on a PC running Strathclyde Whole Cell Program (J. Dempster, University of Strathclyde, Scotland). Data simulations for kinetic analysis used software written by Prof. R. M. Wightman (University of North Carolina, Chapel Hill, NC) to fit experimental data curves (concentration vs time) with theoretical curves that simulate the concentration of DA detected ([DA] at a CFM probe after a single stimulus pulse and DA uptake by a transporter (DAT) operating with Michaelis-Menten kinetics (described by $K_{\mathrm{m}}$ and $V_{\mathrm{max}}$ ). The profile of extracellular DA released into the extracellular space because of a single pulse appears as an instantaneous concentration increase, $[\mathrm{DA}]_{\mathrm{p}}$, followed by a rapid decline that is caused predominantly by transporter-mediated uptake (Giros et al., 1996). This profile can be described by $d[\mathrm{DA}] / d t=[\mathrm{DA}]_{1}-V_{\mathrm{ma}} /\left\{\left(K_{\mathrm{m} /[\mathrm{DA}])}+1\right\}\right.$. This model has been described previously in detail (Wightman and Zimmerman 1990; Kawagoe et al., 1992; Jones et al., 1995) and incorporates a correction for electrode response time caused by surface coatings or other diff usional delays and a decrease in measured response, peak $[\mathrm{DA}]_{\mathrm{o}}$, from true value, $[\mathrm{DA}]_{\mathrm{p}}$. Diffusional delays on these uncoated electrodes were incorporated as a function of DA diff usion through a layer equivalent to a fine Nafion coating of thickness, $d=140-230 \mathrm{~nm}$, as described previously (Cragg et al., 2000). Thin-layer distance, $d$, for each electrode in situ was verified from control data in guinea pig striatum, from multiple best-fit simulations of several single data sets $(>20)$, by constraining $V_{\max }$ and $K_{\mathrm{m}}$ to typical literature values $(2400 \mathrm{~nm} / \mathrm{sec}$ to $3000 \mathrm{~nm} / \mathrm{sec}, 210 \mathrm{nM}$, respectively) (coefficient of determination, $R^{2}>0.9$ ). Best-fit values of [DA $]_{\mathrm{p}}$ and $V_{\text {max }}$ were subsequently determined with this mean, constant $d$, in guinea pig caudatoputamen $(\mathrm{CPu})$ and marmoset putamen. Minimum values of $V_{\max }$ yielding $R^{2}>0.9$ were used to provide the most conservative estimate in marmoset. Small changes in variable parameter values could sometimes give equal degrees of fit (equivalent $R^{2}$ ). Both sets were included for analysis; $n=$ number of simulations. Data simulations were undertaken blind with respect to recording site.

The assumed value of the DAT $K_{\mathrm{m}}$ for both species was the rodent literature value of $210 \mathrm{~nm}$. Although phylogenic conservation of $K_{\mathrm{m}}$ has not been directly demonstrated in situ, the DAT itself is strongly conserved: rat and mouse DAT are $\geq 92 \%$ homologous to human DAT, differing by only one amino acid (Giros et al., 1992; Wu and Gu, 1999). Furthermore, when cloned DAT are expressed stably in cell lines, the absolute potencies $\left(K_{\mathrm{i}}\right)$ of psychostimulants (e.g., D-amphetamine) are highly correlated for rat and human DAT (Giros et al., 1992), and values of $K_{\mathrm{m}}$ (although different from those observed in situ) are similar for mouse and human (Wu and $\mathrm{Gu}$, 1999).

Data are mean $\pm \mathrm{SEM}$, and sample size, $n$, is the number of recording sites unless stated otherwise. The number of animals in each sample ranges from 3 to 10 . Comparisons for differences in means were assessed by oneor two-way ANOVAs and post hoc multiple comparison $t$ tests (NeumanKeuls). In pulse train experiments, $t_{i}$ is the time of initial peak [DA $]_{\mathrm{o}}$, and $t_{s s}$ is the period during a control stimulation train when $[\mathrm{DA}]_{\mathrm{o}}$ is typically at steady state. Note, steady state does not necessarily occur when uptake or autoreceptors are overridden by antagonists and/or at some high frequencies. $\mathrm{CPu}$ is guinea pig caudatoputamen, and putamen refers only to marmoset.

Solutions. All drugs and solutions were obtained from Sigma (St. Louis, MO) except GBR 12909 (RBI, Natick, MA) and TTX (Tocris). In $\mathrm{Ca}^{2+}$. free solutions, $\mathrm{CaCl}_{2}$ was substituted with equimolar $\mathrm{MgCl}_{2}$.

\section{RESULTS}

\section{Identification of evoked release of DA}

A single, electrical stimulus pulse in marmoset putamen evoked the rapid release and removal of the electroactive substance DA (Fig. $1 A)$. The substance was identified as DA by a characteristic voltammogram with peak potentials for oxidation $(\sim 500 \mathrm{mV})$ and reduction currents (approximately $-200 \mathrm{mV}$ vs $\mathrm{Ag} / \mathrm{AgCl}$ ) that are identical for exogenously applied DA and DA signals obtained in guinea pig and rat $\mathrm{CPu}$ here and previously (Fig. 1A) (Cragg and Greenfield, 1997; Cragg et al., 2000). The metabolite DOPAC did not contribute significantly to evoked signals: inhibition of monoamine oxidases A and B for up to $5 \mathrm{hr}$ (pargyline, $20 \mu \mathrm{M}$ ) had no effect on the magnitude of signal observed $(n=4$; data not illustrated).

Release was abolished in a reversible manner in $\mathrm{Ca}^{2+}$-free/ $\mathrm{Mg}^{2+}$-substituted media ( $n=3$; data not illustrated) or in the
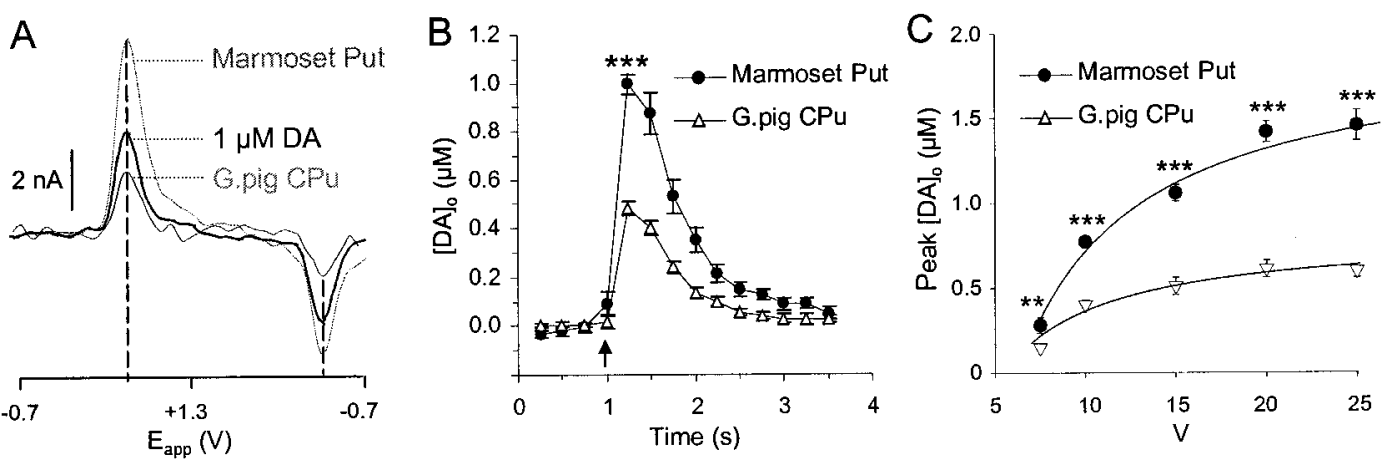

Figure 1. Basic characteristics of evoked release of striatal DA. A, Typical voltammograms obtained after a single pulse in marmoset putamen (Marmoset Put) and guinea pig CPu (gray lines) and in the presence of applied DA (1 $\mu \mathrm{M}$, black line). Peak oxidation and reduction potentials for DA (approximately $+500 \mathrm{mV}$ and $-180 \mathrm{mV}$, respectively, vs Ag/AgCl) are indicated by dashed lines. Calibration, $2 \mathrm{nA}$. B, Mean plots of [DA] versus time evoked by a single pulse (arrow, $0.1 \mathrm{msec}$ ) in marmoset mid-putamen $(\mathbf{\bullet}, n=19)$ and guinea pig mid-CPu $(\triangle, n=23)$. Peak [DA] is significantly greater in marmoset putamen. $C$, Mean peak $[\mathrm{DA}]_{\mathrm{o}}$ versus stimulation intensity $(V)$ in marmoset putamen and guinea pig $C$ Pu. Release is voltage dependent in both species (one-way ANOVAs, $p<0.001$, hyperbolic curve fits $R^{2}>0.97$ ). [DA] is greatest in marmoset putamen at each voltage tested $\left(4<n<23\right.$ ). ${ }^{* *} p<0.01$, $* * * p<0.001$. 


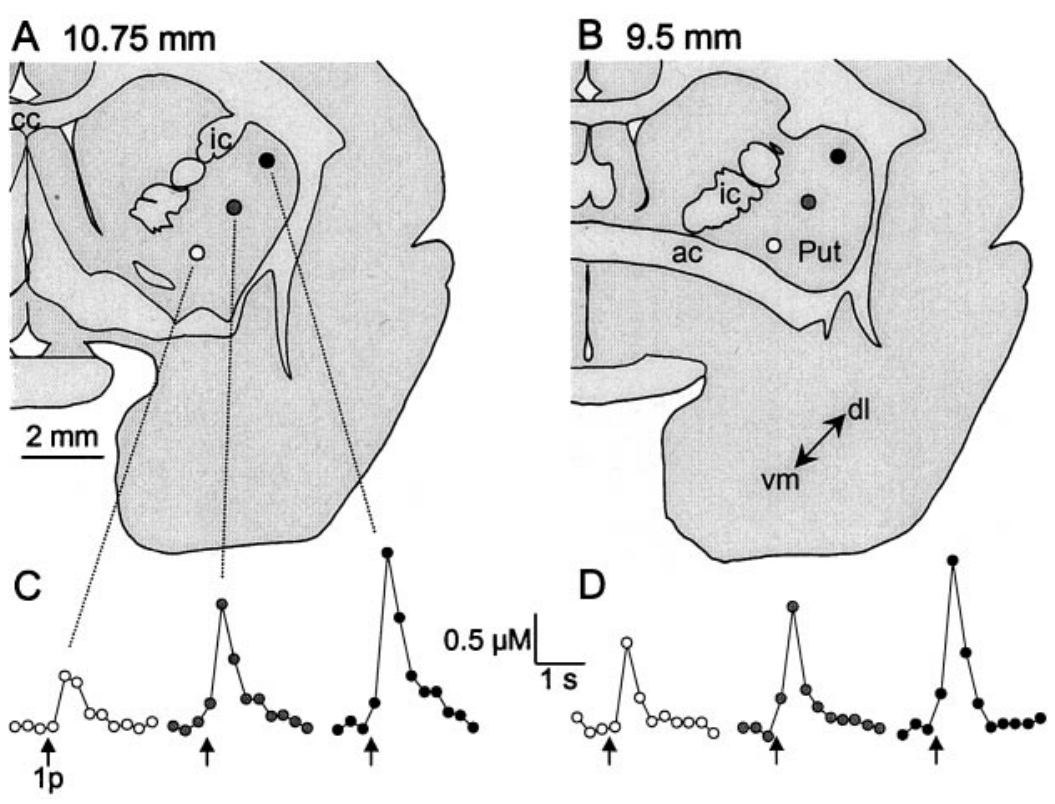

Figure 2. Regional variation in single pulse-evoked $[\mathrm{DA}]_{\mathrm{o}}$ between domains of marmoset putamen. $A, B$, Schematic illustrations of right hemispheres of coronal sections of marmoset striatum at two coordinates, 10.75 and $9.5 \mathrm{~mm}$ anterior to bregma, indicating typical ventromedial-dorsolateral recording sites. Lateral is to the right. $c c$, Corpus callosum; $i c$, internal capsule; $a c$, anterior commissure; $P u t$, putamen. $C, D$, Typical $y$ - $t$ plots of $[\mathrm{DA}]_{\mathrm{o}}$ versus time after a single pulse (arrows) at three ventromedial-dorsolateral coordinates within single slices at each of the AP coordinates depicted in $A$ and $B$. At both AP coordinates, $[\mathrm{DA}]_{\mathrm{o}}$ varies according to medial-lateral coordinates: $[\mathrm{DA}]_{\mathrm{o}}$ evoked in ventromedial putamen (open circles) are less than those in mid-putamen (gray circles), which in turn are less than in dorsolateral putamen (filled circles). Calibration: $0.5 \mu \mathrm{M}, 1 \mathrm{sec}$. presence of TTX ( $1 \mu \mathrm{M})$ ( $n=3$; data not illustrated). Mean peak $[\mathrm{DA}]_{\mathrm{o}}$ evoked by a single pulse $(0.1 \mathrm{msec})$ was significantly greater in mid-putamen (Fig. $1 B)(1.0 \pm 0.04 \mu \mathrm{M}, n=19)$ than in guinea pig mid-CPu $(0.48 \pm 0.03 \mu \mathrm{M}, n=23, p<0.001)$. [DA] in guinea pig is equivalent to that observed in the rat with the same stimuli in this experimental setup (data not illustrated). This approximately twofold difference in [DA $]_{\mathrm{o}}$ attributable to a single stimulus pulse in primate versus rodent striata was not caused by an overall difference in voltage sensitivity: the difference was maintained across a range of stimulus voltages tested (Fig. 1C) (two-way ANOVA, $F_{(1,42)}=220.1, p<0.001$; post hoc $t$ tests, putamen vs $\mathrm{CPu}, p<0.001-0.01)$. The stimulation intensity used in all subsequent experiments was approximately half-maximal in both species.

\section{Regional variation in single pulse-evoked [DA] between striatal domains}

The evoked [DA] observed in marmoset mid-putamen (Fig. 1) was not representative of those seen throughout the putamen: there was significant regional variation in evoked $[\mathrm{DA}]_{\mathrm{o}}$ within marmoset putamen attributable to the ventromedial-dorsolateral (Fig. 2) (two-way ANOVA, $F_{(2,46)}=18.8, p<0.001$ ) but not the anteriorposterior coordinate (two analysis groups: anterior, A10.5-11.5 $\mathrm{mm}$; posterior, A9.5-10.5 mm). Evoked [DA] in dorsolateral putamen was typically 1.5 - to twofold greater than in mid-putamen and two to three times greater than that released ventromedially throughout the anterior-posterior range of putamen investigated (Fig. 2) $(n=4-22)$.

When data from the anterior-posterior range of putamen investigated were collated, the mean peak $[\mathrm{DA}]_{\mathrm{o}}$ values evoked by a single pulse in three regions along the ventromedial-dorsolateral axis were all significantly different from each other (Fig. 3A) (post hoc $t$ tests, all $p<0.001, n=11-30)$ : ventromedial, $0.63 \pm 0.06 \mu \mathrm{M}$; mid (as Fig. 1), $1.0 \pm 0.03 \mu \mathrm{M}$ (159\% of ventromedial); and dorsolateral, $1.86 \pm 0.13 \mu \mathrm{M}$ (296\% of ventromedial).

This gradient in evoked $[\mathrm{DA}]_{\mathrm{o}}$ cannot be fully appreciated with a typical rodent model (Fig. $3 B, C$ ). There was significant regional variation in $[\mathrm{DA}]_{\mathrm{o}}$ evoked within guinea pig $\mathrm{CPu}$ along a ventromedial-dorsolateral axis (Fig. $3 B$ ) (one-way ANOVA, $F_{(2,47)}=$ $3.2, p<0.001)$. However, although the concentration gradient detected in marmoset putamen was over a $300 \%$ concentration
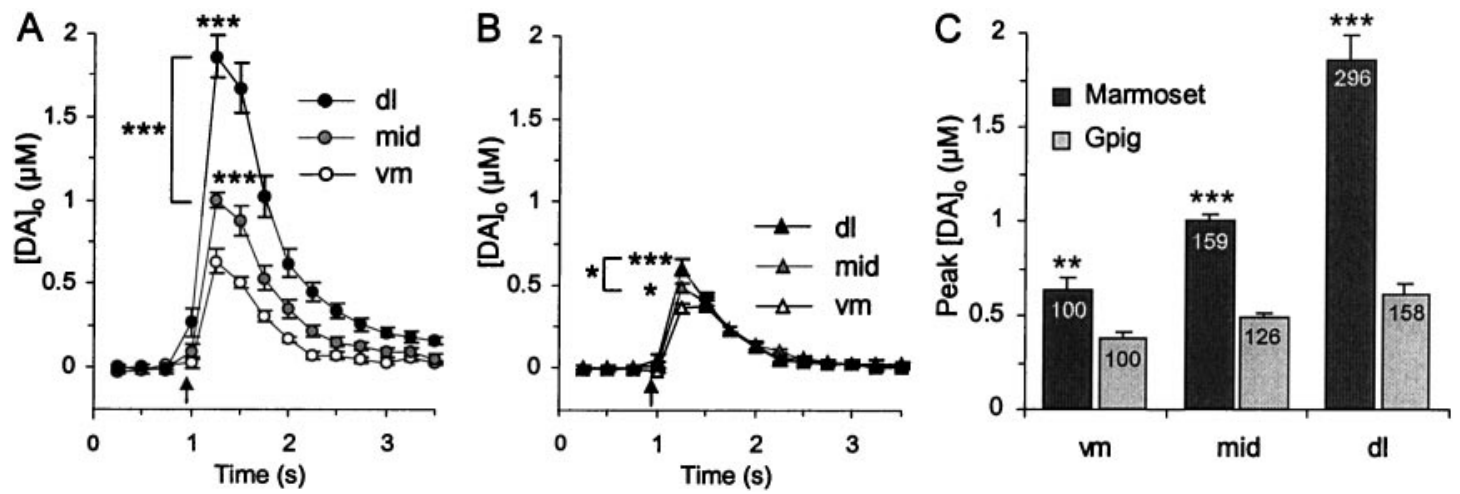

Figure 3. Regional variation in $[\mathrm{DA}]_{\mathrm{o}}$ in marmoset versus guinea pig striata. $A, B$, Mean $[\mathrm{DA}]_{\mathrm{o}}$ versus time evoked by a single pulse (arrows) at varying ventromedial $(\mathrm{vm})$ to dorsolateral $(\mathrm{dl})$ coordinates in $(A)$ marmoset putamen and $(B)$ guinea pig $\mathrm{CPu} . A$, In marmoset putamen, lateral variation in $[\mathrm{DA}]_{\mathrm{o}}$ over a threefold range of concentration (one-way ANOVA, $F_{(2,57)}=3.16, p<0.001$ ) was attributable to significant differences between each of the three regions. ${ }^{* *} p<0.001$ versus ventromedial unless indicated otherwise; post hoc $t$ tests. $B$, In guinea pig $\mathrm{CPu}$, there was a small but significant lateral variation in peak [DA $]_{\mathrm{o}}$ over only a 1.5 -fold concentration range (one-way ANOVA, $F_{(2,47)}=3.2, p<0.001$ ) because of significant differences between each of the three regions. ${ }^{*} p<0.05,{ }^{* * *} p<0.001$ versus ventromedial unless indicated otherwise; post hoc $t$ tests. $C$, Comparison of mean peak [DA] evoked by a single pulse in marmoset putamen versus guinea pig $\mathrm{CPu}$ at each ventromedial-dorsolateral coordinate indicates differences attributable both to species (two-way ANOVA, $F_{(1,103)}=62.03, p<0.001$ ) and region (two-way ANOVA, $F_{(2,103)}=25.78, p<0.001$ ). [DA] $]_{\mathrm{o}}$ is greater in marmoset putamen than guinea pig CPu at all loci. $*^{* *} p<0.01,{ }^{*} * p<0.001$ versus guinea pig; post hoc $t$ tests. Effect of lateral coordinate is most pronounced in marmoset. Inset numbers are $[\mathrm{DA}]_{\mathrm{o}}$ expressed as a percentage of ventromedial in that species. 


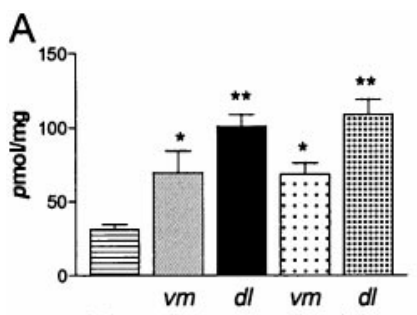

NAcc Putamen Caudate

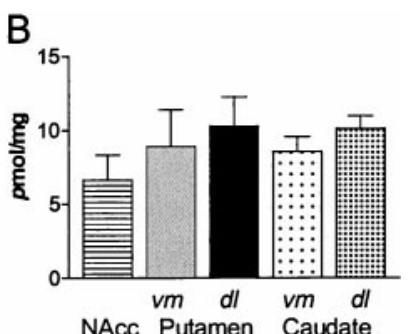

NAcc Putamen Caudate
Figure 4. DA and DOPAC content of marmoset striatum. A, DA content in $\mathrm{pmol} / \mathrm{mg}$ (wet weight). Dopamine content in the dorsolateral and ventromedial caudate and putamen were significantly higher than those levels observed in the nucleus accumbens (NAcc) (one-way ANOVA; $F_{(410)}=$ 10.16, followed by Student Newman-Keuls, ${ }^{*} p<<0.01$, ${ }^{*} p<0.05$, c.f nucleus accumbens). There is a clear trend toward higher levels in dorsolateral compared with ventromedial regions. $B$, DOPAC content in $\mathrm{pmol} / \mathrm{mg}$ (wet weight). DOPAC content did not vary significantly between regions, although lower levels in the accumbens and higher levels in the dorsolateral regions paralleled the pattern observed in DA content.

range (micromolar), the heterogeneity in $[\mathrm{DA}]_{\mathrm{o}}$ in guinea pig $\mathrm{CPu}$ was only over half the range (nanomolar) (Fig. 3). Mean peak $[\mathrm{DA}]_{\mathrm{o}}$ values evoked in guinea pig $\mathrm{CPu}$ were ventromedial, $0.38 \pm$ $0.03 \mu \mathrm{M}$; mid (as Fig. 1), $0.48 \pm 0.03 \mu \mathrm{M}$ (126\% of ventromedial, $p<0.001$, post hoc $t$ test); and dorsolateral, $0.60 \pm 0.05 \mu \mathrm{M}(158 \%$ of ventromedial, $p<0.001)$.

Evoked $[\mathrm{DA}]_{\mathrm{o}}$ in marmoset putamen is significantly greater than in guinea pig $\mathrm{CPu}$ at all corresponding loci, ranging from $166 \pm$ $16 \%$ (ventromedial, $p<0.01$, post hoc $t$ tests) to $310 \pm 22 \%$ of $\mathrm{CPu}$ (dorsolateral, $p<0.001$ ).

\section{Striatal DA content}

In marmoset striatum, DA content was highest in the dorsolateral halves of the putamen and caudate (Fig. 4) (145\% and $154 \%$ of ventromedial areas, respectively). DA contents of dorsolateral and ventromedial caudate and putamen were all significantly higher than most ventromedially, in the nucleus accumbens (Fig. 4 $A$ ) (one-way ANOVA, $F_{(4,10)}=10.16$, post hoc Student NewmanKeuls, $p<0.01-0.05)$. DOPAC content, although higher in the dorsolateral region of both the caudate and putamen (118 and $114 \%$ of ventromedial areas, respectively), was not significantly different from levels observed in the accumbens (Fig. 4B). Ratios of DA/DOPAC content ranged from $\sim 5$ to 11 .

\section{DA uptake pharmacology}

DA uptake by the DAT avidly regulated the extracellular concentration and lifetime of DA in marmoset putamen (Fig. $5 A$ ): after a single pulse during competitive inhibition of the DAT by GBR $12909(500 \mathrm{nM})$, the extracellular lifetime and, in turn, availability (peak $\left.[\mathrm{DA}]_{\mathrm{o}}\right)$, across putamen were significantly elevated $\left[[\mathrm{DA}]_{\mathrm{o}}\right.$ : one-way ANOVA, $F_{(1,24}=24.4, p<0.001, n=12$ (four applications)]. Desipramine (300 nM), an uptake inhibitor selective for the NE transporter (NET), had no significant effect on extracellular lifetime or $[\mathrm{DA}]_{\mathrm{o}}$ (Fig. $\left.5 B\right)[n=9$ (three applications) $]$, thus confirming that the substance measured was not NE.

\section{DA uptake and release: $V_{\max }$ and $[D A]_{p}$ from data modeling}

Each experimental observation of $[\mathrm{DA}]_{\mathrm{o}}$ was modeled with simulations of Michaelis-Menten kinetics to evaluate $V_{\text {max }}$ of the DAT and $[\mathrm{DA}]_{\mathrm{p}}$ (Fig. $5 C$ ). For each accepted simulation, $R^{2}$ was $>0.9$.

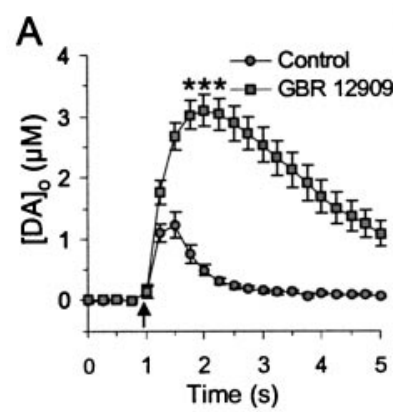

$E$

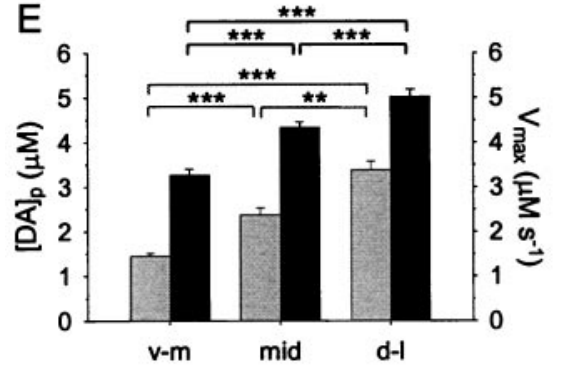

B

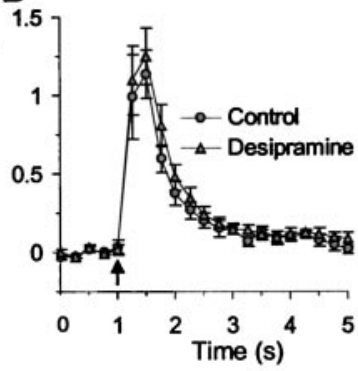

C

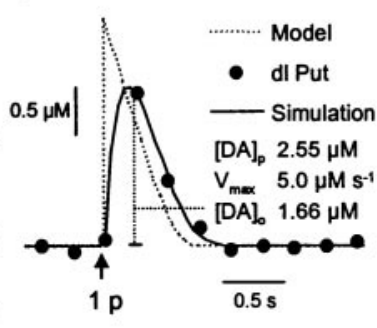

F 7

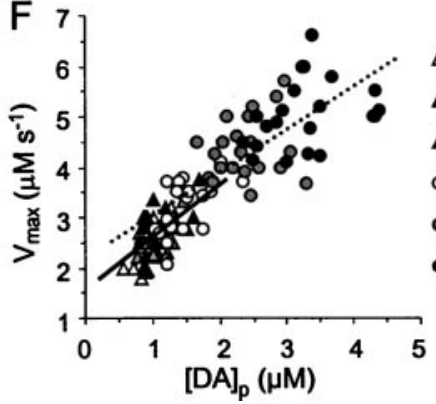

D

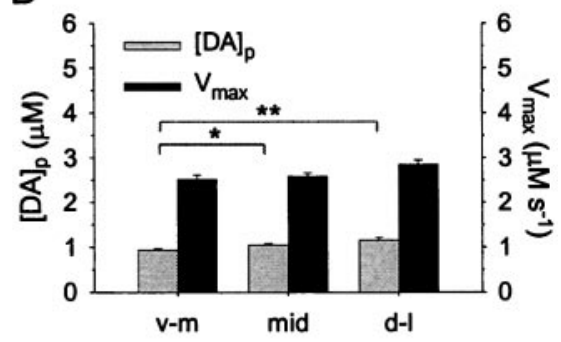

G

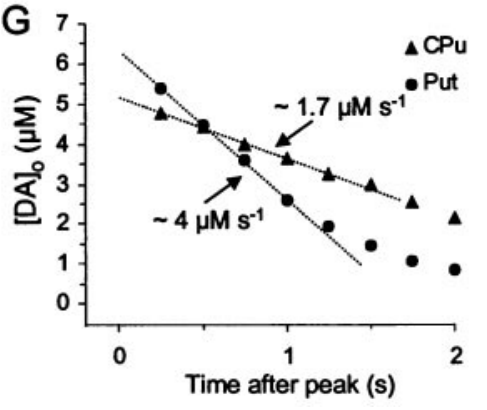

Figure 5. DA uptake: pharmacology and modeling. $A, B$, Mean $[\mathrm{DA}]_{\mathrm{o}}$ versus time evoked by a single pulse (arrows) in marmoset putamen in control and in the presence of an uptake inhibitor for $(A) \mathrm{DA}$ (GBR 12909, $500 \mathrm{nM}$, squares) or $(B)$ norepinephrine (desipramine, $300 \mathrm{nM}$, triangles). A, GBR 12909 slowed rate of removal and significantly enhanced [DA $]_{\mathrm{o}}$ in putamen $\left(n=12,{ }^{* * *} p<0.001\right)$. $B$, Desipramine had no effect on peak [DA] or removal rate $(n=9)$. $C$, Data simulations for determination of $V_{\max }$ and [DA] . Typical simulated data curves (see Materials and Methods) superimposed on raw data points of a single observation in dorsolateral putamen ( $d l$ put $)$ caused by a single pulse (arrow). Simulated data describe the [DA $]_{0}$ detected after release of DA caused by a single pulse ([DA $\left.]_{\mathrm{p}}\right)$ and removal by transporter-mediated uptake operating with Michaelis-Menten kinetics, with (solid curve) and, for comparison, without (dotted curve) a delay attributable to electrode response time (see Materials and Methods). In this example, $R^{2}=0.98, d=155$ $\mathrm{nm}, K_{\mathrm{m}}=210 \mathrm{nM}$; phase delay between stimulation and scan was 20 msec. $D, E$, Graphs of mean $V_{\max }$ and [DA] $]_{\mathrm{p}}$ of simulations in $(D)$ guinea pig CPu and $(E)$ marmoset putamen across a ventromedial $(v-m)$ through dorsolateral $(d-l)$ axis. $D$, There is a small but significant increase in [DA $]_{\mathrm{p}}$ but not $V_{\text {max }}$ with increasing dorsolateral coordinate in guinea pig CPu (one-way ANOVA, $F_{(2,74)}=3.12,{ }^{*} p<0.05, * * p<0.01 ;$ post hoc $t$ tests). E, Both $[\mathrm{DAA}]_{\mathrm{p}}$ and $V_{\max }$ increase significantly with each increase in dorsolateral coordinate in marmoset putamen (** $p<0.01$, ***p $p<0.001$; post hoc $t$ tests). All values of $[\mathrm{DA}]_{\mathrm{p}}$ and $V_{\max }$ in marmoset putamen are significantly greater than in corresponding regions in guinea pig CPu $(p<0.001) . F, \mathrm{Plots}$ of $V_{\text {max }}$ versus $[\mathrm{DA}]_{\mathrm{p}}$ indicate significant positive correlations (lines) for both marmoset putamen (circles) and guinea pig CPu (triangles) $(r=0.82$ and 0.57 , respectively, $p<$ $0.001)$. $G$, Typical decay phases of $[\mathrm{DA}]_{\mathrm{o}}$ after high-intensity stimulation to large $[\mathrm{DA}]_{\mathrm{o}}$ in marmoset mid-putamen and guinea pig CPu using the same electrode. At large $[\mathrm{DA}]_{\mathrm{o}}$, clearance rate approaches $V_{\max }$ (i.e., zero order). Direct comparison of approximate, zero order clearance rates (dotted lines) at the same range of $[\mathrm{DA}]_{\mathrm{o}}$ with the same electrode $(d=215$; see Materials and Methods) indicates an approximately twofold greater clearance rate in marmoset mid putamen than in guinea pig $\mathrm{CPu}$. 

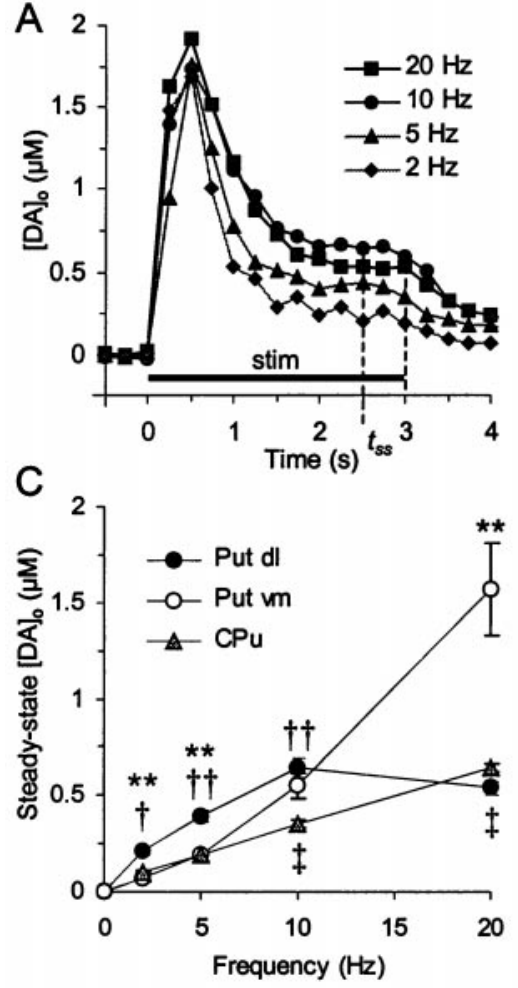

D
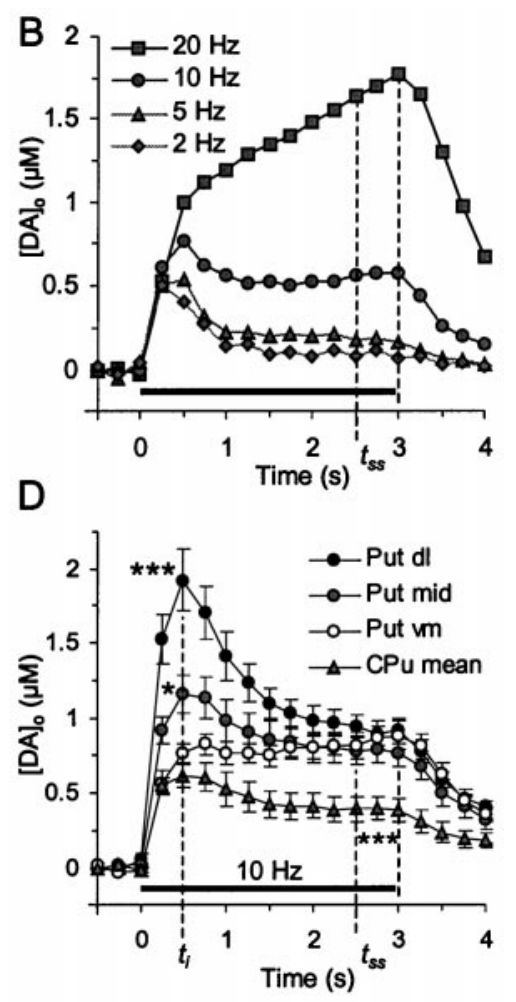

Figure 6. Frequency-sensitivity of steady-state $[\mathrm{DA}]_{\mathrm{o}}$ during pulse trains. $A, B$, Plots of $[\mathrm{DA}]_{\mathrm{o}}$ versus time during $3 \mathrm{sec}$ stimulation trains (stim, solid bar) over a range of frequencies $(2-20 \mathrm{~Hz})$ in $(A)$ dorsolateral and $(B)$ ventromedial putamen, $4<n<8$. SEMs are excluded for clarity. Steady-state [DA] (at $t_{s s}$ ) varies differently with frequency in each domain. $C$, The relationship between $[\mathrm{DA}]_{\mathrm{o}}$ and frequency compared in dorsolateral $(d l)$ and ventromedial $(v m)$ putamen $(P u t)$ and guinea pig $\mathrm{CPu}$. Steady-state $[\mathrm{DA}]_{\mathrm{o}}$ is a function of frequency of stimulation (two-way ANOVA, $F_{(3,41)}=33.9, p<0.001$ ) and region $\left(F_{(2,41)}=4.4, p<0.01\right)$. In dorsolateral putamen, each increase in frequency (up to $10 \mathrm{~Hz}$ ) significantly increased $[\mathrm{DA}]_{\mathrm{o}}$ at $t_{s s}$ (post hoc $t$ tests, $p<0.001-0.01, n=5-8$ ); in ventromedial putamen, $[\mathrm{DA}]$ increased with each frequency above $2 \mathrm{~Hz}(p<0.01-0.05, n=4-7)$; in guinea pig $\mathrm{CPu},[\mathrm{DA}]_{\mathrm{o}}$ at $t_{s s}$ increased with each frequency $(p<0.001-$ $0.01, n=3-4)$. Steady-state [DA $]_{\mathrm{o}}$ in dorsolateral was significantly greater than in ventromedial putamen at frequencies $<10 \mathrm{~Hz}$ and yet significantly less at $20 \mathrm{~Hz}(* * p<0.01)$. Steady-state $[\mathrm{DA}]_{\mathrm{o}}$ values in guinea pig $\mathrm{CPu}$ were significantly less than in dorsolateral putamen at frequencies $<20 \mathrm{~Hz}$ $(\dagger \uparrow p<0.01$ to $\uparrow p<0.05$ ), and less than in ventromedial putamen only at frequencies $>10 \mathrm{~Hz}(\neq p<0.05)$. D, Comparison of $[\mathrm{DA}]$ 。 versus time during $3 \mathrm{sec}$ stimulation trains at $10 \mathrm{~Hz}$ in different domains. At $10 \mathrm{~Hz},[\mathrm{DA}]_{\mathrm{o}}$ at $t_{s \mathrm{~s}}$ does not differ between any region of putamen (ventromedial, mid, and dorsolateral) despite significant variation in initial $[\mathrm{DA}]_{\mathrm{o}}$ (at time $t_{i}$ ) between all three regions ( $t$ tests, $p<0.001-0.05, n=$ 9-15). During $10 \mathrm{~Hz}$ stimulation in guinea pig $\mathrm{CPu}$, steadystate $[\mathrm{DA}]_{\mathrm{o}}$ is significantly less than in all three regions of marmoset $(p<0.001, n=14)$; peak [DA $]_{\mathrm{o}}$ at $t_{i}$ is significantly less than in dorsolateral and mid $(p<0.001)$ but not ventromedial putamen. $* p<0.05$ and $* * * p<0.001$ indicate comparison versus ventromedial putamen.
$[D A]_{\mathrm{p}}$ varied significantly ventromedially-dorsolaterally in parallel with $[\mathrm{DA}]_{\mathrm{o}}$, both in guinea pig $\mathrm{CPu}$ (Fig. $\left.5 D\right)[0.93 \pm 0.04 \mu \mathrm{M}$ (ventromedial) to $1.15 \pm 0.06 \mu \mathrm{M}$ (dorsolateral), one-way ANOVA, $\left.\left.F_{(2,74)}=3.12, p<0.01\right)\right]$ and in marmoset putamen (Fig. 5E) $[1.45 \pm 0.07 \mu \mathrm{M}$ (ventromedial) to $3.38 \pm 0.20 \mu \mathrm{M}$ (dorsolateral), one-way ANOVA, $\left.F_{(2,75}=3.12, p<0.001\right]$, and also between species (two-way ANOVA, $F_{(1,148}=189.7, p<0.001$ ).

Best-fit estimates of $V_{\max }$ were not significantly different between regions in guinea pig $\mathrm{CPu}$ (Fig. $5 D$ ) $[2.52 \pm 0.09 \mu \mathrm{M} / \mathrm{sec}$ (ventromedial) to $2.84 \pm 0.10 \mu \mathrm{m} / \mathrm{sec}$ (dorsolateral), $n=23-30]$, but there was large, significant variation between regions in marmoset putamen (Fig. $5 E$ ) $[3.27 \pm 0.13 \mu \mathrm{M} / \mathrm{sec}$ (ventromedial) to $5.02 \pm 0.16$ $\mu \mathrm{M} / \mathrm{sec}$ (dorsolateral), one-way ANOVA, $p<0.001]$. Two-way ANOVA revealed a significant difference in $V_{\max }$ between species $\left(p<0.001, F_{(1,148}=251.5\right)$ at all corresponding loci (post hoc $t$ tests, $p<0.001)$. $V_{\max }$ was positively correlated with $[\mathrm{DA}]_{\mathrm{p}}$ in both marmoset putamen (Fig. $5 F$ ) (Pearson test, $p<0.001, r=0.82$ ) and guinea pig $\mathrm{CPu}(p<0.001, r=0.57)$. The plot of marmoset data appears to be an extrapolation of the plot of guinea pig data.

By applying a high-intensity stimulation, $[\mathrm{DA}]_{\mathrm{o}}$ can become sufficiently high $\left(\gg K_{\mathrm{m}}\right.$ of the DAT) such that the DAT becomes saturated, and thus clearance rate of DA approaches $V_{\max }$ (i.e., zero order, independent of $[\mathrm{DA}]_{\mathrm{o}}$ and constant with time). This method was used to obtain approximately linear clearance rates $\left(-d[\mathrm{DA}]_{\mathrm{o}} / d t\right)$ at similar $[\mathrm{DA}]_{\mathrm{o}}$ in guinea pig and marmoset to provide an additional, comparative measure of $V$ approaching $V_{\text {max }}$, without dependence on $K_{\mathrm{m}}$. Using the same electrode (and therefore standardized response times), the clearance rate after high-intensity stimulation was approximately linear above low micromolar concentrations in both striata and, in support of the $V_{\max }$ derived by data simulations, was approximately twofold greater in marmoset than guinea pig striata over the same range of $[\mathrm{DA}]_{\mathrm{o}}$ $(n=11-13)$ (Fig. 5G).

\section{Frequency sensitivity of $[\mathrm{DA}]_{\mathrm{o}}$ during pulse trains}

$[\mathrm{DA}]_{\mathrm{o}}$ was compared in ventromedial versus dorsolateral marmoset putamen (and guinea pig CPu) during pulse trains (3 sec duration), over a range of frequencies $(2-20 \mathrm{~Hz})$ at which DA neurons may fire action potentials in situ (Grace and Bunney, 1983, 1984a,b; Schultz et al., 1983; Schultz, 1984, 1986). Evoked [DA] in marmo- set peaked rapidly $\left(t=0.5 \mathrm{sec}, t_{i}\right)$ after the start of the stimulus to a concentration resembling that observed after a single pulse (Fig. 3 ) and subsequently either declined to, remained constant at, or increased to a steady-state concentration (at time, $t_{s s}=2-3 \mathrm{sec}$ ) depending on frequency and region (Fig. $6 A, B$ ). Steady-state $[D A]_{\mathrm{o}}$ attained during pulse trains was a function both of frequency of stimulation (Fig. 6C) (two-way ANOVA, $F_{(3,33)}=31.6, p<$ 0.001 ) and of region (Fig. 6C) (two-way ANOVA, $\mathrm{F}_{(1,33)}=4.4, p<$ $0.05)$. In ventromedial, limbic-associated putamen, each increase in stimulation frequency $(>2 \mathrm{~Hz})$ significantly increased steady-state $[\mathrm{DA}]_{\mathrm{o}}$ (compared with previous frequency) (Neuman-Keuls $t$ test, $p<0.001-0.05)$. In dorsolateral motor putamen, each increase in stimulation frequency significantly increased steady-state [DA] (compared with previous frequency) up to $10 \mathrm{~Hz}$ (Neuman-Keuls, $p<0.001-0.01)$ : at $20 \mathrm{~Hz}$, no further increase in $[\mathrm{DA}]_{\mathrm{o}}$ was observed. $[\mathrm{DA}]_{\mathrm{o}}$ was frequency dependent in guinea pig $\mathrm{CPu}$, with significant increases observed after each increase in stimulation frequency up to $20 \mathrm{~Hz}$ (Fig. 6C) (Neuman-Keuls, $p$ values < $0.001-0.01, n=3-4)$.

Consistent with the regional difference in $[\mathrm{DA}]_{\mathrm{o}}$ observed after a single pulse, $[\mathrm{DA}]_{\mathrm{o}}$ at $t_{s s}$ in dorsolateral putamen was significantly greater (approximately twofold) than in ventromedial putamen at all low frequencies $(<10 \mathrm{~Hz})(t$ tests, $p<0.01, n=3-6)$. However, at $10 \mathrm{~Hz}$, steady-state [DA]。 in dorsolateral putamen was not different from ventromedial (Fig. $6 C, D)(n=15,9)$, and conversely, at $20 \mathrm{~Hz}$, "steady-state" [DA $]_{\mathrm{o}}$ in ventromedial putamen was significantly greater than in dorsolateral putamen $(p<0.01, n=5)$. As a reference point, steady-state $[\mathrm{DA}]_{\mathrm{o}}$ in guinea pig $\mathrm{CPu}$ was significantly less than in dorsolateral marmoset putamen at all frequencies $<20 \mathrm{~Hz}(p<0.001-0.01)$ and less than in ventromedial putamen at frequencies $\geq 10 \mathrm{~Hz}(p<0.01-0.05)$.

\section{[DA] at $\boldsymbol{t}_{s s}$ versus $\boldsymbol{t}_{i}$}

At a stimulation frequency of $10 \mathrm{~Hz},[\mathrm{DA}]_{\mathrm{o}}$ in marmoset putamen reaches a steady state at a concentration that does not differ between any region of putamen (ventromedial, mid, and dorsolateral) (Fig. 6C,D) (range $0.77 \pm 0.09 \mu \mathrm{M}$ to $0.97 \pm 0.09 \mu \mathrm{M}, n=$ $9-15)$. On the other hand, initial peak [DA] $]_{\mathrm{o}}\left(\right.$ at $\left.t_{i}\right)$ is markedly different in all three regions (post hoc $t$ tests, $p<0.001-0.05$ ) as demonstrated previously for single-pulse studies (Figs. 1-3). Thus, 
Figure 7. Regulation of steady-state $[\mathrm{DA}]_{\mathrm{o}}$ by uptake and autoreceptors. $A, C$, Mean $[\mathrm{DA}]_{\mathrm{o}}$ versus time during $3 \mathrm{sec}$ stimulation trains $(10 \mathrm{~Hz}$, solid bar $)$ in ventromedial $(\mathrm{vm})$ and dorsolateral $(d l)$ marmoset putamen in control (circles) and in the presence (squares) of the $(A)$ DA uptake inhibitor GBR $12909(500 \mathrm{nM})$ or $(C)$ autoreceptor antagonist sulpiride $(1 \mu \mathrm{M}) . B, D$, Ratio of [DA] $]_{\mathrm{o}}$ in dorsolateral versus ventromedial putamen at $t_{i}$ and at $t_{s s}$ in controls and $(B)$ GBR 12909 or $(D)$ sulpiride. $A$, GBR 12909 significantly enhanced evoked $[\mathrm{DA}]_{\mathrm{o}}$ throughout putamen $(n=4, * * * p<0.001$, cf. controls). $B$, The ratios of $[\mathrm{DA}]_{\mathrm{o}}$ in dorsolateral versus ventromedial putamen illustrate that $[\mathrm{DA}]_{\mathrm{o}}$ in control is significantly greater in dorsolateral than ventromedial putamen at $t_{i}$ but not $t_{s s}$ (as in Fig. 6D), unless GBR 12909 is present: $[\mathrm{DA}]_{\mathrm{o}}$ at $t_{s s}$ in GBR is slightly but significantly greater in dorsolateral than ventromedial putamen $(* * * p<0.001$ vs ventromedial). The ratio of dorsolateral to ventromedial $[\mathrm{DA}]_{\mathrm{o}}$ at $t_{s s}$ in GBR 12909 remains less than the ratio observed in control at $t_{i}$ (dotted line). $C$, Sulpiride significantly enhanced evoked [DA $]_{\mathrm{o}}$ throughout putamen $(n=7, * * * p<$ 0.001 , cf. controls) after $0.5 \mathrm{sec}$ of stimulation (see also Cragg and Greenfield, 1997). (d) The ratios of [DA] in dorsolateral versus ventromedial putamen illustrate that $[\mathrm{DA}]_{\mathrm{o}}$ at $t_{s s}$ becomes significantly greater in dorsolateral than ventromedial putamen when in the presence of sulpiride $\left({ }^{* * *} p<0.001\right.$ vs ventromedial). The ratio of dorsolateral to ventromedial $[\mathrm{DA}]_{\mathrm{o}}$ at $t_{s s}$ in sulpiride approaches the ratio observed in control at $t_{i}$ (dotted line).
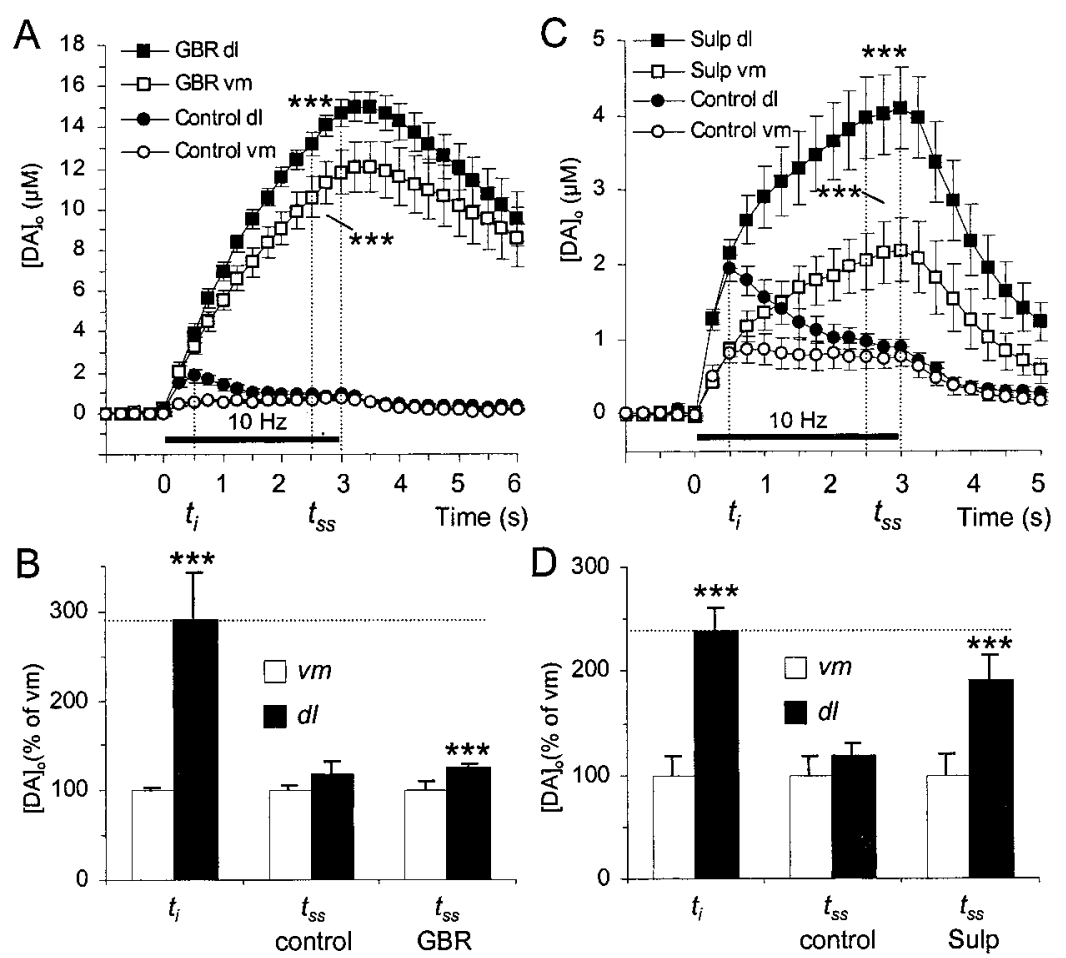

the relationship between $[\mathrm{DA}]_{\mathrm{o}}$ at $t_{i}$ versus $t_{s s}$ is apparently regulated differently in each region: initial $[\mathrm{DA}]_{\mathrm{o}}$ at $t_{i}\left(\right.$ or $[\mathrm{DA}]_{\mathrm{p}}$ in single pulse studies) does not predict steady-state $[\mathrm{DA}]_{\mathrm{o}}$ maintained at this or higher (Fig. $6 \mathrm{~B}, 20 \mathrm{~Hz}$ ) frequencies. In other words, release must be controlled differently during ongoing depolarization in ventromedial versus dorsolateral putamen (see below). By comparison, during $10 \mathrm{~Hz}$ stimulation in guinea pig mid-CPu, steady-state $[\mathrm{DA}]_{\mathrm{o}}$ is significantly less than in all three regions of marmoset ( $t$ tests, $p<0.001, n=14$ ), despite equivalent [DA] $]_{\mathrm{o}}$ at $t_{i}$ to ventromedial putamen.

\section{Regulation of net [DA] at physiological firing rate in marmoset putamen: uptake}

During a train of stimulus pulses, autoregulatory processes, such as autoreceptor feedback and DA uptake between pulses, regulate net [DA] (Wightman and Zimmerman 1990; Limberger et al., 1991; Kawagoe et al., 1992; Cragg and Greenfield, 1997). In the case of autoreceptors, regulation is different at $t_{i}$ and $t_{s s}$ (Trout and Kruk 1992; Cragg and Greenfield, 1997). The mechanisms by which steady-state $[\mathrm{DA}]_{\mathrm{o}}$ is regulated in primate striatum were explored further in ventromedial and dorsolateral marmoset putamen at the frequency $(10 \mathrm{~Hz})$ at which steady state $[\mathrm{DA}]_{\mathrm{o}}$ values were similar. By inhibiting DA uptake, GBR 12909 (500 nM) significantly enhanced $[\mathrm{DA}]_{\mathrm{o}}$ (at $t_{s s}$ ) evoked by a $10 \mathrm{~Hz}$ stimulation train in both ventromedial and dorsolateral regions of marmoset putamen (Fig. $7 A)(1723 \pm 177$ and $1666 \pm 81 \%$, respectively, $n=4, t$ tests $p<$ 0.001 in both regions). Although in control, steady-state [DA] in dorsolateral versus ventromedial putamen is not significantly different, in the presence of GBR 12909, $[\mathrm{DA}]_{\mathrm{o}}$ at $t_{s s}$ was slightly but significantly greater in dorsolateral than ventromedial putamen (Fig. $7 A, B)(p<0.001)$. However, the ratio of dorsolateral to ventromedial $[\mathrm{DA}]_{\mathrm{o}}$ at $t_{s s}$ did not approach the ratio seen at $t_{i}$ (Fig. $7 B$ ). Given this discrepancy in ratios at $t_{i}$ versus $t_{s s}$, an additional mechanism or mechanisms must be differently operational in the regulation of [DA] at $t_{i}$ versus $t_{s s}$.

\section{Regulation of $[\mathrm{DA}]_{\mathrm{o}}$ at physiological firing rate in marmoset putamen: autoreceptors}

By inhibiting presynaptic $\mathrm{D}_{2}$-like autoreceptors, sulpiride $(1 \mu \mathrm{M})$ significantly enhanced $[\mathrm{DA}]_{\mathrm{o}}$ evoked by a $10 \mathrm{~Hz}$ stimulation train after $>0.5 \mathrm{sec}$ of stimulation in both ventromedial and dorsolateral regions of marmoset putamen (Fig. $7 C$ ) to $283 \pm 54$ and $453 \pm$ $60 \%$, respectively ( $n=7, p<0.001$ in both cases). Note that initial $[\mathrm{DA}]_{\mathrm{o}}<0.5 \mathrm{sec}$ (and single pulse-evoked $[\mathrm{DA}]_{\mathrm{o}}$, data not illustrated) is not controlled by autoreceptors. Autoreceptors are not constitutively activated at rest in vitro in slice preparations either of rodents (Trout and Kruk, 1992; Cragg and Greenfield, 1997), or as now demonstrated here, of the marmoset (Fig. $7 C$ ). Although in control, net steady-state $[\mathrm{DA}]_{\mathrm{o}}$ in dorsolateral versus ventromedial putamen is not significantly different, in the presence of sulpiride, $[\mathrm{DA}]_{\mathrm{o}}$ at $t_{s s}$ was significantly greater in dorsolateral than ventromedial putamen (Fig. $7 C, D)(p<0.001)$. The ratio of dorsolateral to ventromedial $[\mathrm{DA}]_{\mathrm{o}}$ at $t_{s s}$ approached the ratio seen at $t_{i}$ (Fig. 7D).

\section{DISCUSSION}

This study demonstrates how extracellular DA is dynamically controlled in the primate putamen and how such DA dynamics differ between limbic- and motor-associated domains. These findings not only lend themselves to an understanding of striatal DA signaling in the primate brain, but they also may be central to understanding the effects of cocaine and regional vulnerability to DA loss in PD (Hornykiewicz, 1966; Elsworth et al., 1987; Kish et al., 1988; Moratella et al., 1992; Antonini et al., 1995). For example, such regional heterogeneity in DA homeostasis may clearly be accompanied by regional vulnerability to DA-related mechanisms of parkinsonian cell death such as DA-dependent oxidative stress and vulnerability to DAT-dependent toxins (Olanow and Tatton, 1999).

\section{Characteristics and regional heterogeneity in single pulse-evoked [DA]。}

DA was released from marmoset putamen and guinea pig $\mathrm{CPu}$ by voltage-sensitive $\mathrm{Na}^{+}$channel- and $\mathrm{Ca}^{2+}$-dependent exocytoticlike mechanisms, but with a two- to threefold species difference in $[\mathrm{DA}]_{\mathrm{o}}$. Because mean tissue DA content of marmoset putamen was approximately double the documented levels in guinea pig $\mathrm{CPu}$ (Wetherell et al., 1989), these (and other, see below) data together suggest a species difference in striatal innervation or DA packing density. Phylogenic differences in extent and density of DA innervation have been observed previously in cerebral cortex (Berger et al., 1991). How interspecies variation in DA availability/packing 
density impinges on postsynaptic neuromodulation will further depend on receptor expression levels, affinities, and effector coupling.

Furthermore, $[\mathrm{DA}]_{\mathrm{o}}$ was a function of the ventromedial-dorsolateral domain: $[\mathrm{DA}]_{\mathrm{o}}$ in dorsolateral, motor-related putamen was $300 \%$ of that in ventromedial, limbic-associated putamen. This extent of variation was not predicted from guinea pig $\mathrm{CPu}$ data (only $\sim 150 \%$ variation). However, variations in $[\mathrm{DA}]_{\mathrm{o}}$ within primate putamen mirror the variations in basal $[\mathrm{DA}]_{\mathrm{o}}$ along a parallel axis within the caudate of rhesus monkeys (Bradberry et al., 2000), and because they reflect, at least in part, tissue DA content, are probably caused by variable DA innervation or other packing density.

\section{DA uptake and release: $V_{\max }$ and $[D A]_{p}$ from data modeling}

DAT, a major site of action for psychostimulants (e.g., cocaine, amphetamine) (Giros et al., 1996), and not the NET, was pivotal in determining $[\mathrm{DA}]_{\mathrm{o}}$ and lifetime in marmoset putamen as previously defined in rodent $\mathrm{CPu}$ (Giros et al., 1996). Data simulations of release and Michaelis-Menten uptake revealed that not only $[\mathrm{DA}]_{\mathrm{p}}$ (consistent with $[\mathrm{DA}]_{\mathrm{o}}$ ) but also $V_{\max }$ varied significantly within the putamen. This was not the case in rodent $\mathrm{CPu}$ : a small regional variation in $\left[{ }^{3} \mathrm{H}\right]$-mazindol binding density (Marshall et al., 1990; Cline et al., 1995) was reflected in only a trend toward variation in $V_{\max }$. Because $V_{\max }$ is a function of the concentration (and turnover number) of the DAT, greater $V_{\max }$ values in dorsolateral primate putamen indicate greatest concentrations of the DAT in motor (PD susceptible) striatum. This hypothesis is strongly supported by (1) a similar ventromedial-dorsolateral gradient of density of $\left[{ }^{3} \mathrm{H}\right]$-cocaine-binding and $\left[{ }^{3} \mathrm{H}\right]$-CFT (WIN $35,428)$-binding sites (25-40\% elevation dorsolaterally) in the putamen of squirrel monkeys (Kaufman and Madras, 1991, 1992; Madras and Kaufman, 1994), (2) the regional neurotoxicity of the DAT substrate, 1-methyl-4-phenyl-pyridinium $\left(\mathrm{MPP}^{+}\right) / \mathrm{MPTP}$ (Elsworth et al., 1987; Moratella et al., 1992), and (3) DAT mRNA expression levels in dorsolateral- versus ventromedial-projecting mesostriatal cells (Shimada et al., 1992; Blanchard et al., 1994; Hurd et al., 1994; Sanghera et al., 1994; Haber et al., 1995). Furthermore, concurrent elevations of $V_{\max }$, [DA $]_{\mathrm{p}}$, and DA content in dorsolateral putamen are consistent not only with increased DAT expression but also with increased axonal density.

$V_{\max }$ (and pseudolinear, zero-order clearance rates) in marmoset putamen were approximately double corresponding values in rodent $\mathrm{CPu}$ in this study and previously in rat in vitro (Jones et al., 1995; Cragg et al., 2000). Comparative data are not yet available regarding DAT expression level or turnover number (molecules transported per transporter per second) in both species; however, the correlated elevation of $V_{\max }$ with [DA $]_{\mathrm{p}}$ supports the hypothesis of greater DA innervation density in primate striatum. Species variations in $[\mathrm{DA}]_{\mathrm{o}}$ and $V_{\max }$ have important consequences for extrapolation of sensitivity to therapeutic, abused, and toxic drugs that require access to the DAT. Higher doses of the psychostimulants cocaine and D-amphetamine/methamphetamine are routinely required in rodents than in primates for experimental and neurotoxic actions (Davis et al., 1978; Melega et al., 1998); although they are caused in part by differing drug metabolism (Melega et al., 1998), dose differences may also result from underlying variation in DAT [or DAT/VMAT (Miller et al., 1999)] activity.

\section{Frequency sensitivity}

$[\mathrm{DA}]_{\mathrm{o}}$ evoked by pulse trains better reflects the integrated dynamics occurring during ongoing neuronal firing in situ. Mesostriatal DA neurons in vivo demonstrate two modes of spontaneous neuronal discharge: single spiking at low, irregular frequencies $(0.5-8$ $\mathrm{Hz}$ ) or bursts with interspike rates of $\sim 13-20 \mathrm{~Hz}$ (or instantaneously higher, task-related) (Aghajanian and Bunney, 1973; Bunney et al., 1973; Grace and Bunney, 1983, 1984a,b; Schultz et al., 1983; Schultz, 1986). There were notable differences in frequencysensitivity of steady-state $[\mathrm{DA}]_{\mathrm{o}}$ between functional domains. At low frequencies $(5 \mathrm{~Hz})$, regional (and species) differences in [DA] paralleled those observed in single-pulse studies. However, at high frequencies $(>10 \mathrm{~Hz})$, when the ability to remove extracellular DA between pulses and neuronal repolarization rate become limiting in the control of $[\mathrm{DA}]_{\mathrm{o}}$, net $[\mathrm{DA}]_{\mathrm{o}}$ in ventromedial putamen exceeded those dorsolaterally. This behavior is not clearly any simple concentration-response function of initial [DA] $]_{\mathrm{o}}$ because steadystate $[\mathrm{DA}]_{\mathrm{o}}$ values in ventromedial putamen also greatly exceeded those in guinea pig $\mathrm{CPu}$ despite equivalent initial [DA]

This difference in frequency-sensitivity of $[\mathrm{DA}]_{\mathrm{o}}$ within primate putamen indicates that despite an increased DA availability in dorsolateral putamen indicated by single-pulse studies and DA content, the largest range of $[\mathrm{DA}]_{\mathrm{o}}$ occurs paradoxically in limbic rather than motor striatum. Similar findings have been described in rat for $\mathrm{CPu}$ versus nucleus accumbens (NAc) in vitro (Trout and Kruk, 1992). These differences may thus reflect as yet unclarified differences between mesolimbic versus motor-associated DA projections that are common across species in the regulation of releasable transmitter pools, presynaptic excitability/repolarization (Jackson, 1995; Meir et al., 1999), and/or differential regulation of $[\mathrm{DA}]_{\mathrm{o}}$ by the presynaptic mechanisms described below. Intriguingly, Horvitz (2000) has speculated that rigid homeostatic control of $[\mathrm{DA}]_{\mathrm{o}}$ in sensorimotor striatum would permit temporal precision that is suited to facilitate switching of response components of a behavioral act. In contrast, limbic-associated target sites associated with motivational, mood states or working memory might require less temporal precision in control of $[\mathrm{DA}]_{\mathrm{o}}$ and even a sustained accumulation of $[\mathrm{DA}]_{\mathrm{o}}$.

\section{Regulation of $[D A]_{\circ}$ at physiological firing rate by uptake and autoreceptors}

Both DA uptake and autoreceptor control of release were powerful regulatory mechanisms of net $[\mathrm{DA}]_{\mathrm{o}}$ at a physiological firing rate in marmoset putamen, as previously observed in rodent striata (Wightman and Zimmerman, 1990; Limberger et al., 1991; Kawagoe et al., 1992; Cragg and Greenfield, 1997; Cragg et al., 1997). Furthermore, both mechanisms demonstrated a ventromedial-dorsolateral variation in activity between putaminal domains. Intriguingly, despite the higher DA content and single pulse-evoked [DA] in the region most susceptible to deinnervation in PD (dorsolateral putamen $),[D A]_{0}$ is in fact most restricted in this region by these presynaptic homeostatic mechanisms.

Stricter homeostatic control of $[\mathrm{DA}]_{\mathrm{o}}$ by uptake in dorsolateral putamen is in agreement with the elevated $V_{\max }$ of the DAT that we report, and yet an increase in DA transmission in mesostriatal circuits by cocaine, caused at least in part by inhibition of the DAT (Roberts et al., 1977; Ritz et al., 1987; Volkow et al., 1997), is most pronounced in vivo in ventromedial striatum of primates (Bradberry et al., 2000) and rodents (Carboni et al., 1990; Cass et al., 1992; Kuczenski and Segal, 1992). Thus, although the reinforcing effects of cocaine may not depend solely on DAT inhibition (Rocha et al., 1998), the magnitude of elevation of striatal [DA $]_{\mathrm{o}}$ by cocaine may depend not only on DAT inhibition but also on the activities of mesostriatal and regulatory afferent projections and other mechanisms of control of $[\mathrm{DA}]_{\mathrm{o}}$. For example, our finding that autoreceptor control is also less stringent in ventromedial putamen, consistent with lower $\mathrm{D}_{2}$-dopamine receptor mRNA levels in mesolimbic projections (Hurd et al., 1994; Haber et al., 1995) (and less stringent homeostatic regulation of $[\mathrm{DA}]_{\mathrm{o}}$ at high depolarization frequencies), may thus be one such factor contributing to the loci of cocaine effect.

\section{Conclusions}

By investigating the dynamic control of $[\mathrm{DA}]_{\mathrm{o}}$ within the marmoset putamen, we have determined for the first time features of the release, uptake, and autoreceptor control of DA in the nonhuman primate putamen. A basic finding that emerges is that striatal DA dynamics and inter-regional variation in primates can only be partly appreciated with a rodent scenario. Extrapolation to primates must take into account these differences in availability and extracellular dynamics of DA. 
Moreover, we have illustrated how, in primate striatum, different functional striatal domains are differentiated by heterogeneous regulation of $[\mathrm{DA}]_{\mathrm{o}}$. The regional differences in DA dynamics observed here between limbic- and motor-associated functional domains of the intact putamen known to be differently susceptible to both modulation by cocaine and degeneration in PD may thus be of key consequence not only to the normal functioning of the striatum but also in drug abuse and susceptibility to degeneration.

\section{REFERENCES}

Aghajanian GK, Bunney BS (1973) Central dopaminergic neurons: neurophysiological identification and responses to drugs. In: Frontiers in catecholamine research (Snyder SH, Usdin E, eds), pp 643-648. London: Pergamon.

Alexander GE, DeLong MR (1985) Microstimulation of the primate neostriatum: II. Somatotopic organization of striatal microexcitable zones and their relation to neuronal response properties. J Neurophysiol 53:1433-1446.

Antonini A, Vontobel P, Psylla M, Gunther I, Maguire PR, Missimer J, Leenders KL (1995) Complementary positron emission tomographic studies of the striatal dopaminergic system in Parkinson's disease. Arch Neurol 52:1183-1190.

Berger B, Gaspar P, Verney C (1991) Dopaminergic innervation of the cerebral cortex: unexpected differences between rodents and primates. Trends Neurosci 14:21-27.

Blanchard V, Raisman-Vozari R, Vyas S, Michel PP, Javoy-Agid F, Uhl G, Agid Y (1994) Differential expression of tyrosine hydroxylase and membrane dopamine transporter genes in subpopulations of dopaminergic neurons of the rat mesencephalon. Mol Brain Res 22:29-40.

Bradberry CW, Barrett-Larimore RL, Jatlow P, Rubino SR (2000) Impact of self-administered cocaine and cocaine cues on extracellular dopamine in mesolimbic and sensorimotor striatum in rhesus monkeys. J Neurosci 20:3874-3883.

Bunney BS, Walters JR, Roth RH, Aghajanian GK (1973) Dopaminergic neurons: effect of antipsychotic drugs and amphetamine on single cell activity. J Pharmacol Exp Ther 185:560-571.

Carboni E, Tanda GL, Frau R, Di Chiara G (1990) Blockade of the noradrenaline carrier increases extracellular dopaine concentrations in the prefrontal cortex: evidence that dopamine is taken up in vivo by noradrenergic terminals. J Neurochem 55:1060-1070.

Cass WA, Gerhardt GA, Mayfield RD, Curella P, Zahniser NR (1992) Differences in dopamine clearance and diffusion in rat striatum and nucleus accumbens following systemic cocaine administration. J Neurochem 59:259-266.

Cline EJ, Adams CE, Larson GA, Gerhardt GA, Zahniser NR (1995) Medial dorsal striatum is more sensitive than lateral dorsal striatum to cocaine inhibition of exogenous dopamine clearance: relation to $\left[{ }^{3} \mathrm{H}\right]$ mazindol binding, but not striosome/matrix. Exp Neurol 134:135-149.

Cragg SJ, Greenfield SA (1997) Differential autoreceptor control of somatodendritic and axon terminal dopamine release in substantia nigra, ventral tegmental area and striatum. J Neurosci 17:5738-5746.

Cragg SJ, Rice ME, Greenfield SA (1997) Heterogeneity of dopamine release and reuptake in substantia nigra, ventral tegmental area and striatum. J Neurophysiol 77:863-873.

Cragg SJ, Clarke DJ, Greenfield SA (2000) Real-time dynamics of dopamine released from neuronal transplants in experimental Parkinson's disease. Exp Neurol 164:145-153.

Crutcher MD, DeLong MR (1984) Single cell studies of the primate putamen. I. Functional organization. Exp Brain Res 53:233-243.

Davis WM, Bedford JA, Buelke JL, Guinn MM, Hatoum HT, Waters IW, Wilson MC, Braude MC (1978) Acute toxicity and gross behavioural effects of amphetamine, four methoxyamphetamines, and mescaline in rodents, dogs and monkeys. Toxicol Appl Pharmacol 45:49-62.

Elsworth JD, Deutch AY, Redmond Jr DE, Sladek Jr JR, Roth RH (1987) Effects of 1-methyl-4-phenyl-1,2,3,6,-tetrahydropyridine (MPTP) on catecholamines and metabolites in primate brain and CSF. Brain Res 415:293-299.

Garris PA, Ciolkowski EL, Pastore P, Wightman RM (1994) Efflux of dopamine from the synaptic cleft in the nucleus accumbens of the rat brain. J Neurosci 14:6084-6093.

Giros B, El Mestikawy S, Godinot N, Zheng K, Han H, Yang-Fen T, Caron MG (1992) Cloning, pharmacological characterisation and chromosome alignment of the human dopamine transporter. Mol Pharmacol 42:383-390.

Giros B, Jaber M, Jones SR, Wightman RM, Caron MG (1996) Hyperlocomotion and indifference to cocaine and amphetamine in mice lacking the dopamine transporter. Nature 379:606-612.

Goldman-Rakic PS, Selemon LD (1986) Topography of corticostriatal projections in nonhuman primates and implications for functional parcellation of the neostriatum. In: Cereb cortex, Vol 5 (Jones EG, Peters A, eds), pp 447-466. New York: Plenum.
Grace AA, Bunney BS (1983) Intracellular and extracellular electrophysiology of nigral dopaminergic neurons. I. Identification and characterisation. Neuroscience 10:301-315.

Grace AA, Bunney BS (1984a) The control of firing pattern in nigral dopamine neurons: single spike firing. J Neurosci 4:2866-2876.

Grace AA, Bunney BS (1984b) The control of firing pattern in nigral dopamine neurons: burst firing. J Neurosci 4:2877-2890.

Haber SN, McFarland NR (1999) The concept of the ventral striatum in nonhuman primates. Ann NY Acad Sci 877:33-48.

Haber SN, Ryoo H, Cox C, Lu W (1995) Subsets of midbrain dopaminergic neurons in monkeys are distinguished by different levels of mRNA for the dopamine transporter: comparison with the mRNA for the $\mathrm{D}_{2}$ receptor, tyrosine hydroxylase and calbindin immunoreactivity. J Comp Neurol 362:400-410.

Hazrati L-N, Parent A (1992) The striatopallidal projection displays a high degree of anatomical specificity in the primate. Brain Res 592:213-227.

Hornykiewicz O (1966) Dopamine (and 3-hydroxytyramine) and brain function. Pharmacol Rev 18:925-964.

Horvitz JC (2000) Mesolimbocortical and nigrostriatal dopamine responses to salient non-reward events. Neuroscience 96:651-656.

Hurd YL, Pristupa ZB, Herman MM, Niznik HB, Kleinman JE (1994) The DA transporter and DA D2 receptor mRNAs are differentially expressed in limbic- and motor-related subpopulations of human mesencephalic neurons. Neuroscience 63:357-362.

Jackson MB (1995) Presynaptic excitability. Int Rev Neurobiol 38:210-251.

Jones EG, Coulter JD, Burton H, Porter R (1977) Cells of origin and terminal distribution of corticostriatal fibers arising in the sensory-motor cortex of monkeys. J Comp Neurol 173:53-80.

Jones SR, Garris PA, Kilts CD, Wightman RM (1995) Comparison of dopamine uptake in the basolateral amygdaloid nucleus, caudateputamen and nucleus accumbens of the rat. J Neurochem 64:2581-2589.

Jones SR, Gainetdinov RR, Wightman RM, Caron MG (1998) Mechanisms of amphetamine action revealed in mice lacking the dopamine transporter. J Neurosci 18:1979-1986.

Kaufman MJ, Madras BK (1991) Severe depletion of cocaine recognition sites associated with the dopamine transporter in Parkinson's-diseased striatum. Synapse 9:43-49.

Kaufman MJ, Madras BK (1992) Distribution of cocaine recognition sites in monkey brain: II. Ex vivo autoradiography with $\left[{ }^{3} \mathrm{H}\right]-\mathrm{CFT}$ and $\left[{ }^{125} \mathrm{I}\right]-$ RTI-55. Synapse 12:99-111.

Kawagoe KT, Garris PA, Wiedemann DJ, Wightman RM (1992) Regulation of transient dopamine concentration gradients in the microenvironment surrounding nerve terminals in the rat striatum. Neuroscience 51:55-64.

Kish SJ, Shannak K, Hornykiewicz O (1988) Uneven pattern of dopamine loss in the striatum of patients with idiopathic Parkinson's disease. N Engl J Med 318:876-880.

Kuczenski R, Segal DS (1992) Differential effects of amphetamine and dopamine uptake blockers (cocaine, nomifensine) on caudate and accumbens dialysate dopamine and 3-methoxytyramine. J Pharmacol Exp Ther 262:1085-1094.

Kunzle H (1975) Bilateral projections from precentral motor cortex to the putamen and other parts of the basal ganglia. Brain Res 88:195-209.

Kunzle H (1977) Projections from the primary somatosensory cortex to basal ganglia and thalamus in the monkey. Exp Brain Res 30:481-492.

Kunzle H (1978) An autoradiographic analysis of the efferent connections from premotor and adjacent prefrontal regions (areas 6 and 9) in macaca fascularis. Brain Behav Evol 15:185-234.

Limberger N, Trout SJ, Kruk ZL, Starke K (1991) "Real-time" measurement of endogenous DA release during short trains of pulses in slices of rat neostriatum and nucleus accumbens: role of autoinhibition. Naunyn Schmiedebergs Arch Pharmacol 344:623-629.

Lynd-Balta E, Haber SN (1994) The organization of midbrain projections to the striatum in the primate: sensorimotor-related striatum versus ventral striatum. Neuroscience 59:625-640.

Madras BK, Kaufman MJ (1994) Cocaine accumulates in dopamine-rich regions of primate brain after i.v. administration: comparison with mazindol distribution. Synapse 18:261-275.

Marshall JF, O’Dell SJ, Navarrete R, Rosenstein AJ (1990) Dopamine high-affinity transport site topography in rat brain: major differences between dorsal and ventral striatum. Neuroscience 37:11-21.

McFarland NR, Haber SN (2000) Convergent inputs from thalamic motor nuclei and frontal cortical areas to the dorsal striatum in the primate. J Neurosci 20:3798-3813.

Melega WP, Lacan G, Harvey DC, Huang S-C, Phelps ME (1998) Dizocilpine and reduced body temperature do not prevent methamphetamineinduced neurotoxicity in the vervet monkey: [ $\left.{ }^{11} \mathrm{C}\right]-W \mathrm{IN} 35,428$-positron emission tomography studies. Neurosci Lett 258:17-20.

Meir A, Ginsburg S, Butkevich A, Kachalsky SG, Kaiserman I, Ahdut R, Demirogoren S, Rahamimoff R (1999) Ion channels in presynaptic nerve terminals and control of transmitter release. Physiol Rev 79:1019-1088

Miller GW, Gainetdinov RR, Levey AI, Caron MG (1999) Dopamine transporters and neuronal injury. Trends Pharmacol 20:424-429.

Moratella R, Quinn B, DeLanney LE, Irwin I, Langston W, Graybiel AM 
(1992) Differential vulnerability of primate caudate-putamen and striosome-matrix dopamine systems to the neurotoxic effects of 1-methyl-4phenyl-1,2,3,6-tetrahydropyridine. Proc Natl Acad Sci USA 89:3859-3863.

Olanow CW, Tatton WG (1999) Etiology and pathogenesis of Parkinson's disease. Annu Rev Neurosci 22:123-144.

Parent A, Mackey A, DeBellefeuille L (1983) The subcortical afferents to caudate nucleus and putamen in primates: a fluorescence retrograde double labelling study. Neuroscience 4:1137-1150.

Rapisarda C, Bacchelli B (1977) The brain of the guinea-pig in stereotaxic coordinates. Arch Sci Biol 61:1-37.

Rice ME, Cragg SJ, Greenfield SA (1997) Characteristics of electrically evoked somatodendritic dopamine release in substantia nigra and ventral tegmental area in vitro. J Neurophysiol 77:853-862.

Ritz MC, Lamb RJ, Goldberg SR, Kuhar MJ (1987) Cocaine receptors on dopamine transporters are related to self-administration of cocaine. Science 237:1219-1223.

Roberts DCS, Corcoran ME, Fiber HC (1977) On the role of ascending catecholaminergic systems in intravenous self-administration. Pharmaco Biochem Behav 6:615-620.

Rocha BA, Fumagalli F, Gainetdinov RR, Jones SR, Ator R, Giros B, Miller GW, Caron MG (1998) Cocaine self-administration in dopaminetransporter knockout mice. Nat Neurosci 1:132-137.

Russchen FT, Bakst I, Amaral DG, Price JL (1985) The amygdalostriatal projections in the monkey. An anterograde tracing study. Brain Res 329:241-257.

Sanghera MK, Manaye KF, Liang C-L, Iacopino AM, Bannon MJ, German DC (1994) Low dopamine transporter mRNA levels in mid-brain regions containing calbindin. NeuroReport 5:1641-1644.

Schultz W (1984) Primate dopamine cell activity in relation to behavioural acts. Clin Neuropharmacol 7:48-49.

Schultz W (1986) Responses of midbrain dopamine neurons to behavioural trigger stimuli in the monkey. J Neurophysiol 55:660-677.

Schultz W, Ruffieux A, Aebischer P (1983) The activity of pars compacta neurons of the monkey substantia nigra in relation to motor activation. Exp Brain Res 51:377-387.

Selemon LD, Goldman-Rakic PS (1985) Longitudinal topography and interdigitation of corticostriatal projections in the rhesus monkey. J Neurosci 5:776-795.

Shimada S, Kitayama S, Walther D, Uhl G (1992) Dopamine transporter mRNA: dense expression in ventral midbrain neurons. Mol Brain Res 13:359-362.

Smith Y, Parent A (1986) Differential connections of caudate nucleus and putamen in the squirrel monkey (Saimiri sciureus). Neuroscience 18:347-371.

Stephan H, Baron G, Schwerdtfeger WK (1980) The brain of the common marmoset (Callithrix jacchus): a stereotaxic atlas. New York: Springer.

Szabo J (1980) Organization of the ascending striatal afferents in monkeys. J Comp Neurol 189:307-321.

Trout SJ, Kruk ZL (1992) Differences in evoked dopamine efflux in rat caudate putamen, nucleus accumbens and tuberculum olfactorium in the absence of uptake inhibition: influence of autoreceptors. Br J Pharmacol 106:452-458.

Volkow ND, Wang GJ, Fischman MW, Foltin RW, Fowler JS, Abumrad NN, Vitkun S, Logan J, Gatley SJ, Pappas N, Hitzemann R, Shea CE (1997) Relationship between subjective effects of cocaine and dopamine transporter occupancy. Nature 386:827-830.

Wetherell JR, Fosbraey P, French MC (1989) A comparison of the distribution of neurotransmitters in brain regions of the rat and guinea-pig using a chemiluminescent method and HPLC with electrochemical detection. J Neurochem 53:1519-1526.

Wightman RM, Zimmerman JB (1990) Control of dopamine extracellular concentration in rat striatum by impulse flow and uptake. Brain Res Bull 15:135-144.

Wu W, Gu HH (1999) Molecular cloning of the mouse dopamine transporter and pharmacological comparison with the human homologue. Gene 233:163-170. 